\title{
O meu bairro: \\ um exercício de cartografia afetiva
}

\section{Adson Cristiano Bozzi Ramatis Lima*}

\begin{abstract}
Resumo No ano de 1949 o escritor francês Léon-Paul Fargue publicou um livro sobre a cidade de Paris intitulado Le piéton de Paris; no capítulo intitulado Mon quartier ele logra traçar uma espécie de "cartografia sentimental" de uma região parisiense compreendida entre duas Estações - a do Norte e a do Leste - e o bairro de la Chapelle, a partir, justamente, do que lhe afetava e lhe fazia voltar a ela tantas vezes. O objetivo desse artigo é demonstrar porque certos lugares de uma cidade são tão - pessoalmente - atrativos e agradáveis, enquanto outros podem nos deixar absolutamente indiferentes.
\end{abstract}

Palavras-chave: cidades, literatura francesa, Paris.

\section{Mi barrio: un ejercicio de cartografía afectiva}

Resumen En 1949, el escritor francés Léon-Paul Fargue publicó un libro sobre la ciudad de París llamado Le piéton París. En el capítulo Mon quartier este autor logra a dibujar una especie de "cartografía emocional" de una región parisina comprendida entre dos estaciones - la del Norte y la del Este - y el barrio de la Chapelle, definiéndola, precisamente, a partir lo que le afectaba y de lo que le motivaba a volver muchas veces. El objetivo de este artículo es demostrar porque ciertos lugares de una ciudad son tan - personalmente - atractivos y agradables, mientras otros tantos nos son absolutamente indiferentes.

Palabras clave: ciudades, literatura francesa, Paris.

\section{My neighborhood: an exercise in affective cartography}

\begin{abstract}
In 1949 the French writer Léon-Paul Fargue published a book about the city of Paris called Le piéton of Paris, in the chapter titled Mon quartier he manages to draw a kind of "sentimental cartography" of Parisian region situated between two stations - the North and East - and the neighborhood of la Chapelle from precisely what affected him. The aim of this paper is to demonstrate why certain places are so - personally - attractive and pleasant, while others may leave us absolutely indifferent.
\end{abstract}

Keywords: citties, french litterature, Paris. 
Em um ensaio publicado em 1949 na coletânea Situations III e intitulado New-York ville coloniale, o filósofo francês Jean-Paul Sartre comentou nesses termos a importância das cidades e dos bairros no modo de vida urbano dos franceses: "Na França, as aglomerações nos cercam e nos protegem: o bairro rico protege os ricos dos pobres; o bairro pobre nos oferece abrigo contra o desprezo dos ricos; da mesma forma, a cidade inteira nos protege da natureza" (2003, p. 87). O filósofo francês procurava traçar um contraponto às cidades norte-americanas que conheceu, pela primeira vez, no ano de 1945, e que teria visitado uma segunda vez um ano mais tarde. As inúmeras cidades norte-americanas que ele teve a ocasião de visitar, naquela época, pareceram-Ihes frágeis, provisórias, com ruas retilíneas que não incitavam ao passeio, e que não protegeriam ninguém dos rigores da natureza, ao ponto que New York ter se assemelhado, no seu imaginário, a uma cidade colonial europeia ${ }^{1}$. De toda sorte, fica evidenciada nesse extrato a importância do bairro como um elemento urbano e, como veremos, não necessariamente administrativamente delimitado - para um francês, o qual significava, sobretudo, proteção, tanto social quanto física. Abrimos o nosso artigo com essa citação porque o nosso objetivo é, justamente, analisar um capítulo do ensaio do escritor francês Paul-Léon Fargue, no qual ele faz um exame da região de Paris onde não residia "[...] havia mais de trinta e cinco anos [...]" (2007, p. 17). O ensaio em questão é o conhecido Le piéton de Paris, e o capítulo mencionado tem o título de Mon quartier. ${ }^{2}$

Contudo, quais teriam sido as motivações de Fargue para realizar tal exame? Deixemos que o próprio autor nos esclareça esse fato: "[...] porque ele [o seu bairro] tem uma fisionomia particular, e ele ganharia em ser conhecido" (2007, p. 17). Ou seja, tratase não apenas de um ex-residente que já não habitava o mesmo endereço havia cerca de trinta e cinco anos, mas, de qualquer sorte, tinha indisfarçável orgulho de, um dia, tê-lo habitado. Mas restaria elucidar quais teriam sido as motivações (nesse caso, as particulares, posto que a geral já é conhecida) que teriam levado esse poeta e ensaísta a escrever uma quase ode a um bairro que sequer era ainda o seu endereço de residência. Novamente, recorramos ao autor:

Há anos que eu sonho em escrever um "Plano de Paris" para pessoas de todo repouso, isto é, para aqueles que passeiam e que têm tempo a perder e que amam Paris. E há anos que eu me prometo começar essa viagem pelo exame do meu bairro [há, aqui, o uso enfático que a língua francesa permite: mon quartier à moi], da estação do Norte e da estação do Leste à Chapelle. (2007, p. 17)

* Adson Cristiano Bozzi Ramatis Lima é Arquiteto e Urbanista, Professor da Universidade Estadual de Maringá, Centro de Tecnologia, Departamento de Arquitetura e Urbanismo. ORCID $<$ https://orcid.org/0000-00017813-5368>
Ora, não foi sem razão que Fargue recebeu o epíteto, justamente, de Le piéton de Paris, título da sua obra mais conhecida cujo um dos capítulos pretendemos analisar nesse artigo. Quando o nosso autor fez menção àqueles que têm "tempo para perder" e que "amam Paris", ele certamente se referia a si mesmo e a alguns dos seus camaradas de letras e de boemia. De qualquer sorte, o texto de Fargue talvez possa ser compreendido, metaforicamente, como uma espécie de "fotografia" (amarelada 
1 É esse sentimento que, justamente, justifica o título do ensaio: New York, cidade colonial.

2 Títulos que podem ser traduzidos, respectivamente, por $O$ pedestre de Paris e Meu bairro.

3 Os bairros, ao contrário dos arrondissements (que podem ser traduzidos por distritos), não são unidades administrativas da cidade de Paris.
${ }^{4}$ No caso, e para ser mais preciso, a imagem de uma parte da cidade de Paris tal como a compreendeu um escritor francês em meados do século XX. Dedicamos uma tese de Doutorado e um estágio Pós-doutoral a esta questão. A este respeito, ver: Lima, Adson Cristiano Bozzi Ramatis. Oscilando entre o ser e o nada: a aventura urbana de Sartre na América. Tese de Doutorado. Faculdade de Arquitetura e Urbanismo, Universidade de São Paulo, São Paulo, 2010. tanto pelo uso quanto pelos anos) de uma região parisiense - e que ele insistia em nomear como bairro, o "seu bairro" 3 -, e que teria sido tirada em 1939, quando havia outra Paris e eram outros os parisienses. Nesse sentido, o nosso objetivo é menos o de recriar espaços desaparecidos do que perceber como um ex-morador não um "simples" ex-morador, mas alguém dotado de talento literário - descreveu a região na qual residiu. Nesse sentido, poder-se-ia afirmar que, muitas vezes, pela força do hábito e devido ao cotidiano que tende a igualar a paisagem, já não se vê mais o que, inicialmente, causava surpresa, e o empreendimento de Fargue é interessante no sentido de que se trata de "resgatar" - ou de desvelar - o que já se ocultava na paisagem urbana para os passantes do cotidiano. Foi por esta razão que usamos, no título do artigo, a expressão "cartografia afetiva", uma vez que se trata, no capítulo Mon quartier, de reconstituir os espaços do seu bairro, imprimindoIhes uma visão pessoal e selecionando tudo aquilo que tenha sido importante para o poeta-morador. Concebemos este termo a partir das observações do filósofo francês Gaston Bachelard:

Todo um passado vem viver, pelo sonho, numa casa nova. A velha locução: "Levamos para a casa nova nossos deuses domésticos" tem mil variantes. E o devaneio se aprofunda de tal modo que, para o sonhador do lar, um âmbito imemorial se abre para além da mais antiga memória. A casa, como o fogo, como a água, nos permitirá evocar, na sequência da nossa obra, luzes fugidias de devaneio que iluminam a síntese do imemorial com a lembrança. Nessa região longínqua, memória e imaginação não se deixam dissociar. Ambas trabalham para o seu aprofundamento mútuo". (1988, p. 25)

Como se pode perceber, pelo devaneio, o filósofo francês cria uma "imagem" que é misto de imaginação e de memória. No caso de Fargue, como não mais residia no "seu bairro", trata-se de um misto de lembrança e imaginação (devemos lembrar que se trata de um ensaio - ou crônica -, isto é, de um texto de caráter literário). Ora, certamente que as cidades não têm o mesmo significado para todos os seus habitantes, os quais, por diversas razões, selecionam partes das cidades e lhes emprestam diferentes sentidos com contrastantes conteúdos emocionais; ou, como escreveu Sartre de maneira mais direta: "[...] há o bairro dos ricos e o bairro dos pobres". Feitas essas considerações iniciais, resta-nos, então, a tarefa principal, a saber, analisar as imagens do texto e saber qual era, exatamente, o bairro de Léo-Paul Fargue.

Contudo, antes de empreender a nossa análise caberia uma observação de caráter metodológico: o uso neste artigo do termo cartografia não se refere, certamente, ao seu caráter científico, isto é, de elaboração de mapas, mas ao ato de "mapear mentalmente" uma dada região. Isto significa que nos transportamos da Geografia para uma região mais vaga e imprecisa, isto é, a do imaginário urbano e, ainda como este pode ser compreendido a partir da literatura. O uso de textos literários como um documento a partir do qual se extrai uma imagem urbana não se faz senão com certa reserva e com certos cuidados, mas acreditamos que o resultado pode ser produtivo e, desta forma, permitir conhecer a cidade que certo extrato de uma sociedade se forma. ${ }^{4}$ 


\section{Meu bairro, mi querencia}

Assim, se cumprirmos de maneira clara os objetivos propostos acima, é necessário reconhecer que o autor iniciou a sua narrativa com um triste e nostálgico lamento sobre as transformações pelas quais teria passado o "seu bairro":

Há trinta e cinco anos, acendiam-se ainda os aquecedores que cheiravam a calças masculinas e a restos de locomotiva, aquecedores mais mornos que quentes, mas famosos em um universo miserável, entorno dos quais os clochards dessa multidão de foras da lei vinham se reunir como moscas ao redor de um bom queijo munster. (2007, p. 17)

O poeta evoca o seu velho bairro e alguns dos seus habitués, descrevendo uma cena em que uma vaga miséria se metamorfoseia em sensações térmicas e fortes odores; o bairro de Fargue parece ser reconstituído (pois é, no fundo, disso que se trata, de uma reconstituição, ofício de todo cartógrafo), e, nesse sentido, não é surpresa que o seu instrumento de trabalho, ao invés da Trigonometria e outros sistemas exatos,

5 Para o crítico inglês J. Middleton Murry, a metáfora é uma capacidade inerente ao homem: "De qualquer maneira que já tenha sido, e talvez processos que tenham sido prevalentes, metáforas são o instintivo e necessário ato pelo qual a mente explora a realidade e ordena a experiência. Isto significa que o menos familiar é assimilado ao mais familiar, o desconhecido ao conhecido: isto confere a um 'nada' uma habitação local e um nome; e dessa maneira isto cessa de ser um "nada" (1975, p. 07). E, ainda: "Toda metáfora e similares podem ser descritas como a analogia pela qual o homem explora o universo da qualidade e mapeia o mundo não mensurável. Dessas indefinidas qualidades, algumas podem ser capazes de uma apreensão sensível direta, ao passo que outras somente podem ser apreendidas por uma faculdade que, apesar de próximas da apreensão sensível, dela difere; [...]" (1975, p. 12). Esta é a opinião de Cortázar: "Foi suficientemente provado que a tendência metafórica é lugarcomum do homem, e não atitude privativa da poesia" (1974, p. 86). tenha sido o mais aproximativo destes: a metáfora ${ }^{5}$. Nessa operação - em que está completamente fora de cogitação observar os astros -, clochards em busca de calor, a partir da escritura, se tornam moscas atraídas pelo forte odor de um queijo germânico. A observar que o autor não faz uso da comparação com o intuito de tornar familiar o que Ihe seria desconhecido (uma vez que ele conhecia muito bem os frequentadores do seu bairro), como na operação clássica do escritor-viajante que somente torna compreensível o exótico na medida em que o aproxima daquilo que já Ihe é conhecido. A metáfora em Fargue é de outra ordem, posto que faz uma inversão: tenta explicar ao leitor que não conheceu o bairro que teve diante de si durante muito tempo (imaginando, é claro, que o pretendido leitor já tenha visto insetos em torno de um alimento de odores fortes e inconfundíveis): ou seja, como se fora um autor estrangeiro que se dirigisse a leitores autóctones. A metáfora torna-se, então, o principal instrumento desse nosso cartógrafo amateur (aqui nos dois sentidos que nos permite a língua francesa: aquele que ama e aquele que ama sem que faça, todavia, desse amor um métier remunerado).

Ora, quando havíamos citado Bachelard, o filósofo francês afirmava, justamente, que "a síntese do imemorial e da lembrança" se dá no espaço em que a imaginação desempenha um papel nada desprezível. Nesse sentido, o queijo escolhido não foi um que possuísse uma "sonoridade francesa", mas a escolha recaiu naquele que remetesse a espaços estrangeiros; assim como os nomes pessoais que, na literatura de Proust, remetem a lugares (POULET, 1992, p. 17), esse queijo é um nome e é, simultaneamente, um lugar, a cidade de Munster, situada em uma das províncias mais germânicas da França: a Alsácia. Dessa maneira, Fargue traça a cartografia do seu bairro parisiense, e parece estendê-lo não apenas além da Paris administrativa, mas mesmo às províncias limítrofes mais ao leste. Mas a busca do exotismo no familiar, nessa "narrativa de viagem invertida", não se limita ao continente europeu, como podemos ler nessas frases: "A fila indiana dos postes de iluminação não substitui o desaparecimento deste acúmulo de lojas que, de dia, torna o bairro comparável a souks africanos" (2007, p. 24). Novamente, o nosso autor transforma o banal de uma rua tantas vezes vista, tantas vezes atravessada, em um exótico bazar magrebino, no qual, em meio a uma grande confusão de homens e de animais, tecidos coloridos se misturam a perfumadas especiarias. 
6 "As pessoas de La Chapelle pensam em servir, em dar conta dos pedidos. estão de olho no presunto, linguado, no alhoporó" (FARGUE, 2007, p. 18).

\footnotetext{
$7 \mathrm{Se}$, de certa maneira o nosso autor tem um "bairro" parisiense apenas para si (posto que não é oficialmente reconhecido pela Prefeitura de Paris, o escritor norte-americano William Faulkner tem, unicamente para si, todo um condado, o ficcional Yoknapatawpha, do qual dizia ser "o seu senhor e único proprietário" (NATHAN, 1991, p. 16).
}

Mas Fargue, aqui como um orgulhoso cronista do seu bairro, vem nos falar melancolicamente da noite, cuja escuridão o esvazia parcialmente, e que os postes mal iluminam as personagens remanescentes: soldados que retornam de um período em um país estrangeiro, prostitutas à Amsterdã, filas nos cinemas que se moviam com a cadência das filas nas consultas gratuitas em hospitais (2007, p. 24). Contudo, o autor teve que admitir as suas preferências: "É também a Chapelle noturna que eu conheço melhor e que eu prefiro" (2007, p. 25). Novamente, temos um bairro que, se não está expandido, tem os seus contornos tão imprecisos quanto às metáforas que os descrevem: ao mesmo tempo africano, portuário, boêmio, e basta tão somente que $\mathrm{o}$ sol se ponha e as lojas se fechem para que os postes iluminem outra realidade, a realidade de um "Éden sombrio, denso e nostálgico" (2007, p. 25). Mas seria apenas isto, o bairro noctâmbulo? Um misto de aventureiros e burgueses atrás dos seus respectivos divertimentos?

Mas não se deve esquecer que se descreve um "bairro" que parece ter sido tão conhecido por Fargue... E que as metáforas não conduzem apenas ao exotismo travestido em cotidiano, ou a aventureiros que buscam ali os prazeres que encontrariam em Amsterdã, e assim, ele afirma: "Um interior burguês entrevisto no segundo piso de uma construção inatacável e rígida como uma base de pirâmide [...]" (2007, p. 25). Ou seja, quando os souks desaparecem deixando o vago traço luminoso dos postes, quando o exotismo não é mais suficiente para explicá-lo a um leitor que, por ventura, não o tenha conhecido, surgem os seus moradores que estavam misturados aos habitués de cada dia: "[...] milhares e milhares de seres que a vida condena a um apartamento insalubre, com um aluguel sórdido e com escadas fervilhando de bacilos, humanidade que nada consola" (2007, p. 24). Uma humanidade que, a cada manhã, lava-se, faz conscienciosamente a barba, para, em seguida, ir ao trabalho, servir aqui um presunto, ali um linguado, e, por vezes, um alho-poró. ${ }^{6}$ Com essas frases premeditadamente anódinas, o cronista nos afastou, de súbito, de uma imagem que perigosamente arriscava a se tornar exótica demais - e, portanto, estereotipada à maneira dos escritores-viajantes, um pouco entre o extremo-leste germânico e o Oriente colonial -, para nos lembrar que se trata de Paris, ainda e sempre Paris. Mesmo a evocação à pirâmide não nos permitiria o devaneio da África, posto que ali seria, simplesmente, a residência de pequenos burgueses atarefados e pouco propensos à poesia e ao devaneio.

Com essas frases o cronista nos recorda que o seu bairro é sério. Mas, e é legítimo que nos perguntemos, de que seriedade ele estaria se referindo? Da seriedade dos gabinetes ministeriais? Ou da seriedade do mundo das grandes finanças? Nada disso, como nos assevera Fargue: "É um lugar agradável, e até mesmo sério. Mas é sério no sentido que a palavra é aplicável a um Bourgogne, a um cassoulet ou a um Brie de Melun. É um prato sério" (2007, p. 18). Ou seja, em tudo o que ali é feito são guardadas a dignidade e a atenção que um ministro ou um industrial reservaria a um dossiê "sério". Os garçons que não tirariam os olhos do presunto, do linguado ou do alho-poró até que estes fossem servidos, e assim não estariam agindo de maneira muito diferente de políticos e financistas, uma vez que estariam sendo "sérios", sem "má-fé" e acreditando piamente na seriedade do seu métier.

Já escrevemos, então, sobre os habituése os moradores do bairro do qual Fargue parecia possuir veleidades de "proprietário"7, mas alhures afirmamos que compreendemos 
8 Aparentemente, Sartre usa o termo "bairro" (quartier em Francês) com o mesmo grau de liberdade que Fargue, ou seja, delimitando-se por conta própria linhas imaginárias (mas nem por isso menos reais) a partir de certos "marcos". Esses marcos eram para Fargue as duas Estações (a do Norte e a do Leste) e o bairro (desta vez, "administrativo") de la Chapelle; para Sartre o seu "bairro" era delimitado pelas Rua des Franc-Bourgeois, Rua Vieille du Temple, Rua de Rivoli e Rua des Rosiers.

9 As cidades e a vida urbana jamais deixaram Sartre indiferente, que escreveu ensaios sobre várias cidades: Paris, é claro, mas, igualmente, New York, Chicago e uma miríade de anódinas cidades norte-americanas. As cidades Italianas de Roma, Veneza e Capri motivaram, igualmente, a sua versátil pena de escritor. A esse respeito ver Referências. o narrador como um cartógrafo que traça as coordenadas afetivas do seu bairro, e é necessário, então, atentar para os seus limites, ao menos como os compreendeu Fargue. Então, vejamos: "[...] da Estação do Norte, e da Estação do Leste à Chapelle" (1997, p.25). Se observarmos um mapa da cidade de Paris, com as suas divisões em bairros e arrondissements, veremos que este espaço não corresponde a nenhuma divisão administrativa, e foi por isto mesmo que Fargue, no início do seu texto, afirmou que começaria o seu "Plano de Paris" por "seu bairro", isto é, por aquele que foi criado e traçado pelo próprio autor, de acordo com as suas memórias, preferências estéticas, e, sobretudo, idiossincrasias as mais diversas. Mais uma vez, é legítimo que reconheçamos que as fronteiras políticas só com muita dificuldade - e com uma boa dose de boa vontade - coincidem com as fronteiras culturais. Por isso a cartografia traçada por Fargue é "afetiva", posto que, tomando-a na sua totalidade, ela só faz sentido para si. Portanto, o mapa traçado "à golpes de metáforas" pelo cronista tem o "seu Magrebe" (em Francês ele teria escrito "mon Mahgreb à moi", assim como ele escreveu "mon quartier à moi"), os seus portos (com marinheiros e prostitutas), os seus miseráveis e os seus pequenos burgueses em seus pequenos apartamentos, indestrutíveis como as "bases de uma pirâmide", e, é claro, com os seus trabalhadores "sérios".

Posto isto, é mister que nos perguntemos porque tanta afeição a um lugar no qual o autor confessa que, além de não ter nascido lá, quando escreveu a sua crônica já não mais o habitava há muito tempo: "Se eu tenho uma ternura particular por esse lugar é que eu quase nasci ali" (2007, p. 19). E: "[...] nós nos deixamos há mais de trinta e cinco anos" (2007, p. 18). O autor, apesar da mera causalidade (o fato de não ter nascido no seu "bairro") e de uma decisão que não é precisada na crônica (o fato de não mais habitá-lo), nunca deixou de Ihe ter grande afeição, e, sempre que possível, ali retornava, à maneira desses animais migratórios que, por razões ditadas pelo instinto, percorrem grandes distâncias para retornar sempre aos mesmos locais. Pensando no bairro particular de Fargue, uma pergunta faz-se quase necessária: por que há espaços aos quais devotamos certa ternura e outros que, ao contrário, nos deixam absolutamente indiferentes?

Para respondermos a essa questão, convocaremos outro intelectual parisiense que, por sua vez, tinha as suas preferências quanto a certos "bairros" de Paris, como podemos perceber nessas frases: "Tudo isso era como um halo ao redor da cabeça de Pieter - o que era injusto! - porque para mim ele tinha a auréola de ter morado naquele bairro onde eu nunca passei de um turista" (SARTRE, 1982, p. 152). ${ }^{8}$ Essas belas e eloquentes frases foram escritas por mais um piéton de Paris, o filósofo JeanPaul Sartre, que lamentava não ter tido a sorte do seu camarada de exército, Pieter, de ter habitado o "bairro"9 pelo qual nutria tanta afeição. Um filósofo tão ligado à vida urbana como Sartre talvez pudesse responder - ao menos parcialmente - a questão que elencamos acima. Ora, no seu tratado de Ontotologia Fenomenológica O ser e o nada, ele escreveu:

Meu lugar se define pela ordem espacial e a natureza singular dos "istos" que a mim se revelam sobre um fundo de mundo. É, naturalmente, o lugar que "habito" (meu "país", com seu solo, seu clima, suas riquezas, sua configuração hidrográfica e orográfica), mas, também, mais simplesmente, a disposição e ordem dos objetos que presentemente me aparecem (uma mesa, do outro lado da mesa uma janela, à 
10 A citação corresponde à parte a) Meu Lugar, do subcapítulo Il Liberdade e Facticidade: a Situação, do Capítulo 1 Ser e Fazer: a liberdade, da Quarta parte Ter, Fazer e Ser.

11 "É impossível que eu não tenha um lugar, caso contrário eu estaria, em relação ao mundo, em estado de sobrevoo, e o mundo, como vimos anteriormente, não iria manifestar-se de forma alguma" (SARTRE, 1997, p. 602).

12 "Assim, devemos dizer que a facticidade de meu lugar só me é revelada na e pela escolha que faço de meu fim" (SARTRE, 1997, p. 607).

13 "Atribui-se a seguinte réplica a um emigrante que estava para deixar a França com destino a Argentina após o fracasso do seu partido político: como alguém observou que a Argentina estava 'muito longe', indagou - 'longe de quê?' E é inegável que, se a Argentina configura-se longínqua àqueles que vivem na França, isso ocorre em relação a um projeto nacional implícito que valoriza o seu lugar de franceses. Para o revolucionário internacionalista, a Argentina é um centro do mundo, como qualquer outro país" (SARTRE, 1997, p. 608). esquerda da janela uma estante, à direita uma cadeira, e, atrás da janela, a rua e o mar) e que me indicam como sendo a própria razão da sua ordem. (1997, p. 602). ${ }^{10}$

Assim, nessa longa citação, se ousarmos substituir o termo "meu lugar" por "meu bairro", veremos que a apropriação de certo espaço - ou um sentimento de "pertencimento" a este - ocorre da mesma maneira que se vai de um lugar que é "afetivamente significado" a outro que gozaria do mesmo estatuto (e, entre ambos, um "quase-nada" de significações vagas e imprecisas). E, parafraseando o filósofo existencialista, diríamos que este "quase-nada" (ou no man's land) seria um mero "fundo de mundo" sem os "istos" que o significariam. E, por outro lado, a razão de ser desses "lugares que habitamos" tem a sua origem, justamente, na sua ordem, na sua natureza singular e na sua disposição. Há, portanto, lugares nos quais nos localizamos e nos quais, por diversas e, às vezes, aleatórias razões, sentimo-nos bem. Todavia, por que tal lugar e não, simplesmente, outro? E, no caso do nosso cronista, por que esse território entre as duas Estações e a Chapelle? Ora, Sartre, que tratou de nos ligar visceralmente a um lugar ${ }^{11}$, poderia, novamente, explicar essa profunda ligação entre o homem e certos espaços? Mais uma vez, consultemos o filósofo francês:

Além disso, esta determinação da localização, que pressupõe a transcendência toda, só pode ocorrer em relação a um fim. É à luz do fim que meu lugar adquire significação. Porque jamais posso ser simplesmente aí: meu lugar é captado, precisamente, como um exílio, ou, o oposto, como esse lugar natural, tranquilizador e favorito [...]. (SARTRE, 1997, p. 606)

Nesse sentido, de acordo com a filosofia que Sartre desenvolveu em O ser e o nada, temos um projeto criado a partir da nossa inalienável liberdade, o que implica tanto escolhas quanto fins. ${ }^{12} \mathrm{E}$ são justamente essas escolhas e fins que definem o caráter do meu lugar: "[...] à luz de meu fim, meu lugar recorda-me simbolicamente este fim em todos os seus detalhes, tanto em suas conexões de conjunto" (SARTRE, 1997, p. 607). Ou seja, se meu projeto não implica permanecer no local em que eu esteja atualmente, o meu lugar será vivido com, talvez, angústia e impaciência13; por outro lado, se este é o local adequado ao meu projeto global de vida, então, ao contrário, esse "meu lugar" será tranquilo e confortável, ou, na linguagem das corridas, uma querencia: "[...] como esse lugar natural, tranquilizador e favorito que Mauriac denominava querencia, por comparação com o lugar ao qual o touro ferido sempre retorna na arena; [...]" (SARTRE, 1997, p. 606). Assim, seguindo esse pensamento, todos nós teríamos o "nosso lugar", o "nosso bairro", e, portanto, a nossa querencia de touro ferido; desde que, naturalmente, estejamos cumprindo um projeto que implique fins e escolhas.

Já poderíamos, então, responder a questão que levantamos alhures. Nós somos mais felizes em certos lugares (não importando o seu estatuto administrativo) que em outros pela simples razão que os primeiros, ao contrário dos segundos, correspondem aos fins que buscamos: no caso de Fargue, estes seriam o de levar uma pequena existência boêmia em meio a prostitutas e marinheiros, mercados "africanos" e pequenos burgueses atarefados. Projeto de vida bem modesto, retorquiriam alguns... Mas, se nem todos escolheram como projeto os grandes feitos, e, portanto, nem tiveram diante de si fins espetaculares (como o exemplo aludido por Sartre), isto não significa que a sua existência foi desprovida de projetos e fins, como nos relata Fargue: 
Eis porque eu me enfeito com o título de poeta dos carpinteiros, dos comerciantes de bicicletas, dos merceeiros, dos horticultores, das floristas e dos chaveiros da Rua de Albervilliers, do cais do Loire, da Rua do Terrage e da Rua das Vinaigriers. Ao vê-los, ao Ihes sorrir, cansados, correndo nas calçadas, ao Ihes perguntar sobre as suas filhas, ao ver seus filhos soldados, eu fico feliz até os mais recônditos segredos do meu velho coração sem ódio. (2007, p. 19)

Lendo estas frases, compreendemos porque aquela região definida pelo autor era o "seu bairro", como a "querencia" aludida por Sartre; ora, se ele não possuía grandes projetos políticos de alterar radicalmente o mundo nas suas estruturas políticas e sociais, se não ele não tinha o desejo de conhecer os locais mais exóticos do mundo (como vimos, ele se contentava largamente com o próprio "exotismo" domesticado e local), nem de conhecer outras pessoas em outras situações, bastando-lhe a vida partilhada com os pequenos burgueses e os pequenos comerciantes locais, então, teremos que reconhecer que a região compreendida pelas Estações do Norte e do Leste com a Chapelle bastava para significar esse "coração sem ódio".

\section{Últimas considerações}

Eis, portanto, uma tentativa de traçar a "cartografia afetiva" de certo "bairro", cujo cronista conhecia tantos "istos" quanto Ihe permitia o seu "fundo de mundo": os exóticos bazares magrebinos (na realidade, tão "exóticos" quanto cartões postais), os postes de iluminação que, à noite, metamorfoseiam o mundo das calçadas, os noctâmbulos de todos os tipos e para todos os gostos, os passantes anódinos, os veículos, os trens, as floristas... Mas, haveria apenas esses "istos" no "fundo de mundo" delimitado pelo nosso autor? Certamente que não, mas deveríamos esperar, então, que outro cronista, um parisiense tão apaixonado quanto Fargue - mas iluminado por outro projeto o qual, por sua vez, implicaria outros fins - traçasse o seu "plano de Paris", com instrumentos tão imprecisos quanto as metáforas do nosso cronista? Deveríamos, então, reconhecer que é da natureza das "cartografias afetivas" se sobreporem, sem, contudo, se igualarem. Se Sartre, por exemplo, confessava a contragosto "não passar de um turista no 'seu bairro'", os seus "istos" naquele "fundo de mundo" não deveriam, eventualmente, coincidir com os de Pieter, que ali residia. Digamos que Sartre talvez escrevesse sobre "seu bairro" um texto de exilado, ou uma narrativa viática, enquanto o seu colega de armas escreveria, se fosse dotado de veleidades literárias, uma crônica de residente ou de ex-residente, à maneira de Mon quartier.

Então, se já sabemos - ainda que vagamente, temos que confessar - porque gostamos mais de certos lugares que de outros, ao menos, e pensando o texto de Fargue a partir da filosofia que Sartre desenvolvia em 1943 (data da primeira publicação de O Ser e o Nada), podemos imaginar como os projetos globais que fazemos (ou deixamos de fazer, o que tem quase o mesmo sentido) afetam a nossa percepção sobre o mundo, inclusive o "fundo de mundo" que nos cerca. Ou, como diria Sartre, o que importa é a liberdade de nos termos escolhido aqui, exatamente aqui, neste lugar e em nenhum outro. Felizes seriam, então, aqueles que se deixam sucumbir a esse projeto, e têm a audácia, de acordo com o seu projeto, de ficar ou de partir. 


\section{Referências bibliográficas}

BACHELARD, Gaston. A poética do espaço. Trad.: Antonio de Padua Danesi. São Paulo: Martins Fontes, 1988.

CORTÁZAR, Julio. Valise de Cronópio. São Paulo: Perspectiva, 1974.

FARGUE, Léon-Paul. Le piéton de Paris. Paris: Gallimard, 2007.

LIMA, Adson Cristiano Bozzi Ramatis. Oscilando entre o ser e o nada: a aventura urbana de Sartre na América. Tese de Doutorado. Faculdade de Arquitetura e Urbanismo, Universidade de São Paulo, São Paulo, 2010.

MURRY, J. Middleton. Methaphore in countries of the Mind, 1-17. In: MARTIN, Graham; FURBANK, P. N. (Orgs). Twentieth Century Poetry. Inglaterra: The Open University Press, 1975.

NATHAN, Monique. Faulkner. Trad.: Hélio Pólvora. Rio de Janeiro: José Olympio,1991.

SARTRE, Jean-Paul. O ser e o nada: ensaio de ontologia fenomenológica. Trad.: Paulo Perdigão. Petrópolis (RJ): Editora Vozes, 1997. New York, cidade colonial. In: Situations, III. Paris: Gallimard, 2003. 